\title{
Fortalecimento do controle social em saúde mental: estratégias e possibilidades
}

\author{
Luís Felipe Ferro
}

Departamento de Terapia Ocupacional, Universidade Federal do Paraná - UFPR, Curitiba, PR, Brasil.

\begin{abstract}
Resumo: A diretriz do controle social tem marco legislativo, com a elaboração da Constituição de 1988. Embora previsto para proporcionar, à população-controle, fiscalização e planejamento conjunto das ações públicas, o controle social ainda apresenta fragilidades em sua aplicação pragmática. A área da saúde, no contexto brasileiro, ainda que pioneira na construção de corpo legislativo para subsidiar as práticas do controle social, não se distancia destas dificuldades. A partir da intenção do enfrentamento desta problemática, foi composto, em 2010, um curso presencial em Curitiba-PR, atualmente em sua décima turma, para proporcionar formação popular para o exercício do controle social das ações públicas em saúde, foco dado ao campo da saúde mental. O artigo que se apresenta procura realizar relato desta experiência por meio da apresentação da estrutura do curso, de seu conteúdo e das estratégias aplicadas durante seu processo maturacional. Pretende-se proporcionar campo crítico-reflexivo para a composição de ações voltadas ao tema do controle social que possibilitem o fortalecimento de populações em vulnerabilidade social e a construção coletiva do Sistema Único de Saúde.
\end{abstract}

Palavras-chave: Saúde Coletiva, Controle Social, Educação em Saúde, Participação Comunitária, Participação Cidadã, Participação Social.

\section{Possibilities of actions to strengthen social control in mental health: strategies and possibilities}

\begin{abstract}
The Social Control guidelines for public policy obtained legislative framework with the drafting of the 1988 Brazilian Constitution. Although expected to provide control, supervision, and joint planning of public actions, Social Control still shows weaknesses in its pragmatic application. In the Brazilian context, the health sector presents similar difficulties in spite of its pioneering role in the construction of a legislative body to support the practice of social control. Aiming to confront this issue, a classroom course it was developed to provide popular education for the exercise of Social Control of public health actions, with focus on mental health. This course started in 2010 in the municipality of Curitiba, and it is currently in its tenth class. This article seeks to report this experience through the presentation of the course structure, content, and strategies applied during its maturation process. It is intended to provide a critical and reflective field for the composition of actions related to the Social Control theme that enable the strengthening of vulnerable populations and the collective construction of the "Sistema Único de Saúde" (Brazilian National Health System).
\end{abstract}

Keywords: Public Health, Social Control, Health Education, Consumer Participation, Citizen Participation, Social Participation. 


\section{Introdução}

Em contexto brasileiro, a partir do final da década de 1970, diversos agentes passaram a se organizar, sistematicamente, para compor críticas incisivas contra o modelo manicomial (AMARANTE, 2003; FERRO, 2009).

Desde a I Conferência Nacional de Saúde Mental, realizada em 1987, vem sendo reforçada a necessidade da elaboração de novas práticas em saúde mental, substitutivas ao modelo manicomial (VIDAL; BANDEIRA; GONTIJO, 2008). Do ponto de vista político-jurídico, um marco importante, no que se refere à reforma psiquiátrica brasileira, foi a aprovação da Lei 10.216, de 2001.

Embora tal movimento discursivo do campo da Saúde Mental não ocorra sem tensionamentos, com posicionamentos distintos de diferentes atores sociais, a política pública da Saúde Mental busca estruturar-se a partir i) da edificação de equipamentos pautados nas diretrizes do acompanhamento clínico aliado à inclusão social, ii) do investimento na ampliação da cidadania e iii) da estruturação de açóes voltadas a responder às demandas dos usuários atendidos e de seu território (BRASIL, 2011).

Paralelamente, diferentes movimentos sociais organizados, sobrepujando a ditadura, tiveram grande conquista com a elaboração da Constituiçáo Federal de 1988. Nossa Carta Magna prevê, em todos os âmbitos, o controle estreito das açóes públicas pela população, possibilitando que diferentes segmentos sociais participem da elaboração e fiscalização das ações públicas. Uma das faces de tal êxito, afirmando contemporaneamente a democracia, vem sendo chamado de Controle Social (CÔRTES, 2009).

O Sistema Único de Saúde (SUS), previsto na Constituição Federal de 1988 e regulamentado pela Lei 8.080, em 1990, afirma o Controle Social das ações públicas em seu corpo textual (BRASIL, 1990a). A Lei 8142 de 1990 (BRASIL, 1990b) também apresentou marco importante na regulamentaçáo da participação da comunidade na gestáo do SUS. Efetivando-se o controle social, prevê a participação da população nas Conferências e nos Conselhos de Saúde, espaços ímpares para a fiscalização e o controle das açôes públicas.

No entanto, o que podemos evidenciar, concretamente, é uma grande lacuna na pragmatização dos conceitos acima expostos. O desconhecimento do controle social - uma de suas inúmeras mazelas - e das formas de controle das açôes públicas pela população, aliado ao insulamento de diferentes gestóes na formulação e condução das políticas públicas, tomam presença generalizada em atual contexto brasileiro. A população atendida pela saúde mental encontra-se ainda mais vulnerável neste processo.

No município de Curitiba, local onde a experiência aqui relatada foi desenvolvida, a IV Conferência Municipal de Saúde Mental - Intersetorial, realizada no ano de 2010, embora regulamentada para compor com $50 \%$ a participaçáo de usuários do SUS, demonstrou, concretamente, tímido envolvimento desta parcela da sociedade. A experiência de participação nesta conferência, conjugada à experiência prévia no campo da saúde mental, reafirmaram um quadro problemático na região: a fragilidade de associações e/ou movimentos de usuários e familiares no controle das açóes públicas.

A elucidação de tal panorama foi propulsora de diferentes ações, com início no ano de 2010. No segundo semestre deste ano, foi ministrada a primeira turma de um curso de controle social, foco dado ao campo da saúde mental, destinado a usuários de serviços de saúde mental, seus familiares e, em turmas posteriores, a profissionais do campo. O curso, vinculado ao estágio de observação do curso de Terapia Ocupacional da Universidade Federal do Paraná, em parceria com a Associação de Apoio aos Portadores de Distúrbios de Ordem Mental (AADOM) e com a Associação Arnaldo Gilberti (AAG), tomou frequência semestral e, atualmente, encontra-se em sua décima turma. Tal processo vem proporcionando terreno reflexivo para o amadurecimento de práticas voltadas ao controle social; em nosso caso, com a especificidade da saúde mental.

É a partir deste ensejo que se apresenta ao leitor a proposta do artigo: relatar essa experiência de ministração e organização de um curso de controle social, tendo como ponto de partida a premissa mais ampla do investimento em práticas que fomentem o controle social das açóes públicas. É intenção proporcionar ao leitor, até o final deste corpo textual, a configuração de uma ação, dentre outras tantas possíveis, para o fortalecimento do controle social.

Contudo, uma prévia mais detalhada sobre o controle social proporcionará terreno mais sólido para o relato da experiência.

\section{Controle social: contextualização}

A década de 1980, no Brasil, foi palco de diversas mudanças na relação Estado-Sociedade, tomando lugar propostas de democratização, principalmente na gestáo das políticas públicas. $\mathrm{O}$ processo de 
democratização proporcionou diferentes transformaçôes nas formas de relacionamento da população com o Estado, a saber: algumas formas autoritárias de gestão das Políticas Sociais foram revistas e, ao menos legislativamente, foi garantida a participação da sociedade no processo decisório (SILVA; CRUZ; MELO, 2007; CORREIA, 2006).

O Controle Social compóe espaço organizativo e estruturado, que prevê o controle das açóes públicas por diferentes sujeitos e suas representatividades: movimentos populares, entidades de classe, sindicatos, governo, entidades jurídicas, prestadores de serviço, entre outros (ASSIS; VILLA, 2003).

Ao longo de um processo contínuo de enfrentamentos, o Controle Social possui importantes conquistas jurídico-institucionais, tais como: a promulgação da Constituição Federal de 1988, que afirma e sustenta a participação da população no controle das açôes públicas, e a Lei 8.080 de 19 de setembro de 1990, que traz em seu capítulo II, artigo 7. ${ }^{\circ}$, inciso VIII, a participação da comunidade na gestâo do SUS como um de seus princípios diretivos.

Para se implantar institucionalmente o Controle Social na organização do Sistema Único de Saúde, foram criados as Conferências e os Conselhos de Saúde nos âmbitos das três esferas governamentais: municipal, estadual e nacional. A descrição e a regulamentação destes equipamentos encontram apoio na Lei 8.142, de 28 de dezembro de 1990. Estas instâncias preveem a participação da comunidade como atores sociais, procurando garantir seu protagonismo no controle das açôes públicas em saúde (CÔRTES, 2009).

$\mathrm{Na}$ sequência, apresentaremos, com maior propriedade, a estrutura dos Conselhos e das Conferências de Saúde, a partir da base legal advinda da Lei 8142/90. Cabe, antes de prosseguirmos, um cerceamento conceitual: diversos autores iniciam sua argumentação sobre o Controle Social a partir de uma contraposiçáo entre o controle do Estado sobre a população e o controle da população sobre as açôes públicas, reservando a este último sua eminência, após a década de 1990 (SANTOS; BASTOS, 2011; CORREIA, 2000). Outros autores, ainda, devido à possível vinculação da expressão Controle Social às práticas regulatórias e dominadoras do Estado frente à população, posicionam-se junto ao conceito de Controle Público, na referência às práticas democráticas de controle das açóes políticas do Estado pela população (OLIVEIRA, 2004; VALLA, 2006).

Ao que se apresenta, acredita-se que o percurso histórico brasileiro vem afirmando, em diversos espaços democráticos, inclusive nos Conselhos e nas Conferências de Saúde ${ }^{1}$, documentos legislativos (BRASIL, 2003b) e em literaturas-guias da área (BRASIL, 2002, 2003a), a expressão Controle Social para referir-se à participação da população no controle e na composição conjunta das açóes públicas.

O conceito de Controle Social é apresentado, ainda, em alguns trabalhos, com certa nebulosidade, ampliando de maneira indefinida - ou até mesmo igualando o conceito à participação social - e estendendo suas estruturas/equipamentos de funcionamento a diferentes instituições de proteção aos direitos humanos. Neste trabalho, adotaremos, afirmando o percurso histórico, por um lado, e para proporcionar maior subsídio para a conjugação com nossa proposta, por outro, o conceito de Controle Social vinculado exclusivamente ao exercício deliberativo e consultivo previstos na Lei 8.142/90 e a seus equipamentos, quais sejam: Conselhos e Conferências de Saúde - tomando como direcionamento a argumentativa sobre a possibilidade de fortalecimento de açôes que culminem na especialização do controle social para a construção coletiva do SUS.

A partir de tal opçáo conceitual, cabe ressaltar a função dos Conselhos e das Conferências de Saúde, estrutura contemporânea para o exercício do Controle Social no SUS. As Conferências de Saúde, com periodicidade máxima de quatro anos, propóem-se a levantar demandas nos diferentes âmbitos em que se realiza. A ideia da conferência é realizar consulta aos diferentes segmentos da população (usuários do SUS, prestadores de serviço, trabalhadores e gestores), por meio de seus representantes, sobre suas demandas no campo da saúde. Como produto final das Conferências de Saúde, um relatório final, que congrega as diferentes propostas discutidas neste espaço, com intenção de guiar as ações públicas, é composto (BRASIL, 1990b).

O Conselho de Saúde, por sua vez, tem caráter permanente e deliberativo. É competência deste órgão colegiado atuar "[...] na formulação de estratégias e no controle da execuçáo da política de saúde na instância correspondente, inclusive nos aspectos econômicos e financeiros [...]" (BRASIL, 1990b).

Alguns dos Conselhos de Saúde organizam-se, ainda, por meio de Comissóes Temáticas. Estas comissóes têm, por diretrizes, discutir, acompanhar e propor ações em Saúde, na circunscrição de seu tema, que subsidiem e fortaleçam as intervençôes do Conselho de Saúde no controle das açôes públicas. O Conselho Municipal de Saúde de Curitiba, a título de exemplo, possui as seguintes comissões temáticas: Comissão de Assistência à Saúde; Comissão de Comunicação e Formação; Comissão de DST/AIDS; Comissão 
de Saúde Ambiental; Comissão de Saúde do Idoso; Comissão de Saúde da Mulher; Comissão Intersetorial de Saúde do Trabalhador; Comissão de Saúde Mental; Comissão de Orçamento; Comissão Intersetorial de Recursos Humanos; Comissão de Saúde da Pessoa com Deficiência; Comissão de Saúde Bucal; Comissáo de Saúde da Criança e do Adolescente; Comissão de Saúde do Homem.

Enquanto prenúncio legislativo, é esperado que o consenso para a defesa de princípios e diretrizes que guiaráo a edificação de um sistema público de saúde seja adquirido por meio do processo de negociação e discussões entre os diversos segmentos participantes dos espaços de controle social (ASSIS; VILLA, 2003). Além disso, os acessos às questóes econômico-financeiras do setor bem como à programação, à execução, ao acompanhamento, à avaliação, à elaboração e à aprovação do plano de saúde devem tomar lugar por meio destes equipamentos (SILVA; CRUZ; MELO, 2007).

Contudo, embora o desenho legislativo do controle social apresente-se como importante conquista, uma grande fenda entre sua previsão legal e a pragmática cotidiana é inegável. As dificuldades são diversas e se instauram no mais basal de nossa formaçáo social, permeando: desconhecimento generalizado da população sobre o tema; relaçóes verticalizadas nos espaços de controle social; despreparo da população para o exercício democrático, tanto no segmento da gestáo como de trabalhadores e usuários; dificuldades das representaçóes no contato com sua base; limitaçôes na fiscalização dos serviços de saúde e da implementação das políticas públicas; desconhecimento da realidade epidemiológica, etc (AVRITZER, 2007; PEDRINI; ADAMS; SILVA, 2007; BRAVO; CORREIA, 2012). Embora o aprofundamento nestas dificuldades desperte interesse ao autor, será necessária resignação, ao menos neste momento, à afirmação da intangibilidade e da inconcretude atual das premissas do Controle Social.

Por ora, reconhecendo a importância de açôes em saúde no fortalecimento do controle social, nos deteremos na exploração da noçáo de empoderamento coletivo.

Carvalho (2004), em crítica à noçáo individualista, por vezes supervalorizada, de empoderamento psicológico, apresenta o conceito de empoderamento comunitário. Para o autor:

Podemos definir o "empowerment" psicológico como um sentimento de maior controle sobre a própria vida que os indivíduos experimentam através do pertencimento a distintos grupos, e que pode ocorrer sem que haja necessidade de que as pessoas participem de açôes políticas coletivas. Influenciando esta formulação encontramos uma perspectiva filosófica individualista que tende a ignorar a influência dos fatores sociais e estruturais; uma visão que fragmenta a condição humana no momento em que desconecta, artificialmente, o comportamento dos homens do contexto sociopolítico em que eles encontram-se inseridos (CARVALHO, 2004, p. 1090).

Quanto ao empoderamento comunitário, o autor sublinha a importância da atenção dos agentes da saúde para a realização de ações que sustentem o fortalecimento de coletivos para a defesa de diferentes pontos que lhe são de demanda, de maneira a conduzi-los a

[...] uma postura ativa de enfrentamento das determinaçóes macro e microssociais da iniquidade social, colocando em questão diferenciais de poder porventura existentes na relação entre especialistas e não-especialistas, entre populações de países ricos e desenvolvidos e de países pobres, entre homens e mulheres, e entre heterossexuais e homossexuais (CARVALHO, 2004, p. 1091).

É a partir deste ponto que se sustenta, aqui, a importância do fortalecimento de coletivos para o exercício do controle das açôes públicas, de maneira a proporcionar a construção compartilhada do SUS e para a defesa dos direitos das diferentes populaçóes.

\section{Curso de controle social: contextualização e preparação}

A vivência proporcionada pela IV Conferência Municipal de Saúde Mental - Intersetorial foi propulsora imediata de açóes voltadas ao fortalecimento do controle social no campo da Saúde Mental, no município de Curitiba. A pouca participação deste segmento e a clara falta de preparo dos poucos, e bravos, representantes que ali estavam, aliados à incipiência de Associações vinculadas ao campo na cidade, proporcionaram o vislumbre nítido do despreparo generalizado deste segmento para a defesa de seus direitos e apresentação de suas demandas.

Ao final do evento, no início do semestre letivo, o estágio de saúde mental do curso de Terapia Ocupacional já tinha um elemento imprescindível para a elaboração de um Projeto Terapêutico Singular Coletivo (OLIVEIRA, 2007). A ideia inicial era estruturar um grupo de controle social, tendo como população-alvo os usuários dos serviços de saúde mental da cidade de Curitiba e seus familiares. 
É notória a dificuldade de participação, principalmente de familiares, em grupos com realização em horário comercial. O que foi pensado, na época, e que se mostrou operacional já em primeiro momento, foi a configuração estratégica deste encontro como curso. Com isto, usuários e familiares, que encontravam impossibilidades de realização de grupos nestes horários, puderam ausentar-se do trabalho na dupla via: se necessário, ressaltando o caráter de atendimento do espaço ou, ainda, utilizando-se de sua qualificação como curso. Familiares e usuários vinculados a empregos públicos, acima de tudo, puderam ausentar-se com facilidade na justificativa da realização de um curso de formação, que contava com expediçấo de certificado.

Vale a explicitação de outra das nuances desta prática, que poderá proporcionar ao profissional que opte por adentrar-se neste complexo terreno, menos arenosidade: a divulgação da iniciativa para interessados. Imaturamente, na primeira turma do curso, contamos, praticamente de maneira exclusiva, com a divulgação da iniciativa tendo como base o apoio dos Centros de Atenção Psicossocial (CAPS) da regiáo. Ligaçóes, disparo de e-mail para estas instituições e encaminhamento de folders foram realizados, contudo nenhuma pessoa foi inscrita desta maneira. Alguns motivos elucubrados, na época, foram: incipiência do tema do controle social na formação dos profissionais da saúde mental; dificuldade no acesso a materiais digitalizados; falta de parcerias operacionais com CAPS; a incipiência do movimento associativista vinculado ao campo da saúde mental.

A primeira turma, logo, contou com apenas seis participantes, que se inscreveram como consequência da divulgação da iniciativa na comemoração do Dia da Saúde Mental, no ano de 2010. Hoje, entendemos que, para tornar mais visível esta ação, vale a iniciativa de realizar: i) prévias parcerias com CAPS e profissionais da regiáo vinculados ao fortalecimento dos direitos humanos; ii) divulgação do curso junto aos espaços de controle social (sejam conselhos de saúde, comissôes, etc); iii) divulgação em associaçóes estruturadas, conselhos regionais, etc. Com a divulgaçáo realizada nestes moldes, a segunda turma já contava com 20 pessoas e, com a inscrição realizada através do site da AADOM, a sexta turma pôde contar com 170 inscritos, o que demandou a ampliação da turma para 50 vagas.

Acreditamos que açôes de natureza semelhante podem se dar nas mais variadas instituiçóes; contudo, talvez maior vinculação temática e concisão junto à proposta de Promoção/Prevenção da Saúde, no campo da saúde, poderia se dar junto às Unidades
Básicas de Saúde, nos Centros de Atenção Psicossocial e, no campo da Assistência Social, nos Centros de Referência de Assistência Social. Para a estruturação concreta do curso/grupo, organizamos, inicialmente, sete encontros com duração de duas horas semanais. Nas duas últimas turmas, o curso foi expandido para dez encontros e pretendemos, em breve, ampliá-lo novamente para 12 encontros. Além disso, atualmente, o curso também conta com a presença de profissionais da saúde e gestores, na intençáo de formar multiplicadores do trabalho.

\section{Controle social e saúde mental: pontos para fortalecimento}

A partir da instauração do encontro, vale a pena citar a forma com que o curso foi estruturado.

Longe de propor pretensa fórmula padrão para a organização destes encontros e afirmando tanto a continuidade infinita deste processo de amadurecimento como a importância de estratégias criativas e vinculadas temporoespacialmente, nossa experiência tomou alguns direcionamentos temáticos que guiaram os encontros: controle social e legislaçáo na área de enfoque. No curso, o qual foi intitulado "Controle Social em Saúde Mental: praticando Cidadania”, abordamos, com o risco da redundância, o tema do controle social. Fugindo da suposta obviedade, ressaltamos a importância do conhecimento pragmático sobre as estruturas do controle social, quais sejam: conferências de saúde; conselhos de saúde; comissões de saúde.

Alguns materiais (BRASIL, 2002) são interessantes para o aprofundamento no tema e proporcionam esclarecimentos sobre o seu funcionamento e a sua base legal. Contudo, vale uma elucidaçáo: nada substitui a vivência nestes espaços. Diversas dificuldades, barreiras, contatos e vislumbres das relaçóes de poder são de inexorável valia para a composição deste trabalho. No entanto, muitas vezes, o tempo hábil para a participação nestes espaços, conforme sugerido, é reduzido na prática profissional. Um ponto que pode ser interessante é a utilizaçáo dos encontros do grupo/curso para compor este amadurecimento de maneira mútua.

Em nossa experiência, criamos, para além do espaço do curso, outro grupo, mais especializado no controle social, o qual foi chamado durante seu percurso de Grupo Avançado de Controle Social (GACS). Com este grupo, fomos participando mutuamente e tomando maior propriedade dos espaços de controle social. 
Uma estratégia que pode ser interessante ao profissional que se aventurar na edificação de um grupo de controle social é o contato prévio com o conselho de saúde, seja municipal, estadual, federal, local, para informe sobre as datas e a frequência das reuniōes destes órgãos ou de suas comissões - "Por quê?", perguntar-se-ia o leitor. A frequência das reunióes dos conselhos municipais ou de uma de suas comissóes é bastante variável nas mais diferentes regiôes/municípios brasileiros; em nossa experiência, as reuniốes acontecem mensalmente. Em posse do conhecimento destas datas, pode ser interessante configurar o encontro com o grupo no mesmo dia e horário das reunióes. Logo, três vezes por mês, o grupo poderia se encontrar para aprofundar-se em determinados temas e, uma vez ao mês, o grupo poderia encontrar-se no espaço do conselho. Desta maneira, a estruturação e a inserçâo concreta dos participantes do grupo/curso nos espaços de controle social podem encontrar respaldo. As reunióes do conselho costumam ser abertas, mas a consulta sobre este ponto, assim como a confirmação de estrutura física, pode, também, ser um bom conselho.

Para além disto, cabe a explicitação de algumas problemáticas evidenciadas em diversas das reuniôes da Comissão de Saúde Mental de Curitiba, no período de 2010 a 2012: a postura verticalizada nos espaços de controle social, tendo os gestores e/ou profissionais da saúde, infortunadamente, com frequência, em seu topo; uso de jargôes; relações de poder e situações de exposição. Ao realizarem suas denúncias ou queixas, não é raro que alguns usuários do SUS, bravos e solitários, que se encaminhem a estes espaços sofram represálias e/ou sejam colocados em situaçōes bastante constrangedoras e intimidadoras. Com isso, o usuário acaba por frequentar uma única e exclusiva vez o espaço, com receio de passar novamente por situações vexatórias. Suas denúncias, ainda, podem ser contornadas de maneira evasiva e sem o devido encaminhamento - o que desmonta a credibilidade dos espaços de controle social e, com isso, a participação popular. $\mathrm{O}$ encontro do grupo/participantes nas reunióes pode, logo, proporcionar aos usuários maior suporte para diversas destas nuances.

Outro ponto que, talvez invariavelmente, acometerá os que se aventurarem nas reunióes do Conselho/ Comissōes é a ampla utilização de jargóes técnicos e siglas, os quais alijam, por si só, muitos de seus participantes. A ação de posicionar o grupo/curso de maneira estratégica, com horário casado às reuniōes do Conselho/Comissão pode possibilitar que o grupo possa trabalhar estes questionamentos/siglas/jargóes em momentos vindouros de seu encontro e, ainda, o esclarecimento instantâneo de certos termos utilizados pode se dar por meio do profissional e/ou alguns dos participantes, proporcionando, em um paralelo excêntrico, mas não descontextualizado, o acionamento da tecla "SAP" e, consequentemente, suporte à participação dos sujeitos.

A legislação na área de enfoque, segundo tema estrutural do curso de controle social, apresentou importância ímpar. Antes de cobrar e fiscalizar açóes públicas, é mister que os participantes tenham pleno conhecimento sobre o que esperar das mesmas. Nosso caso, voltado ao campo da saúde mental, apresenta alguns detalhes exemplares.

A Portaria MS 130/12 (BRASIL, 2012) prevê, a título de exemplificação, a transformação dos CAPSad tipo II, com funcionamento previsto das 8 às $18 \mathrm{~h}$, podendo se estender até às $21 \mathrm{~h}$, para CAPSadIII, com funcionamento $24 \mathrm{~h}$ e equipe expandida, nas capitais dos Estados. A Portaria também impóe a implantação de um CAPSadIII para cada grupo populacional de 200 a 300 mil habitantes. Os usuários de Curitiba, logo, poderiam apoiar-se nesta portaria para reivindicar a instauração do equipamento $24 \mathrm{~h}$, com funcionamento diário, inclusive em feriados e finais de semana, e a implantação de, no mínimo, seis destes equipamentos no município, na medida em que a população atual perfaz 1.746.896 hab. Para além da propriedade quanto aos direitos já instaurados por meio de leis, decretos, portarias, etc., o curso trabalha sobre a compreensão da participação da comunidade na elaboração, (re)configuração ou revogaçáo de determinado corpo legislativo.

Acredita-se que seja importante, pelo menos em atuais configuraçóes sociais brasileiras, dar foco no aprofundamento legislativo de determinada área para o trabalho junto ao controle social, por mais que a crítica sobre o reducionismo possa recair sobre tal declaração. Por quê?

Cada campo da saúde apresenta amplas informaçôes legislativas, cujo aprofundamento é extremamente oneroso, embora, sem dúvidas, contributivo. Pessoas com diabetes têm um histórico em lutas e conquistas que foram edificando corpo legislativo próprio, assim como pessoas que vivem com o HIV e a AIDS, pessoas com deficiência, pessoas com transtornos mentais, etc., e cada incursão envolve tempo amplo e, infelizmente, muitas vezes, impraticável em cotidiano concreto. $\mathrm{O}$ enfoque em determinado tema possibilita maior propriedade das configuraçôes históricas que o campo foi assumindo, assim como maior inteiração dos direitos/políticas públicas/equipamentos - o que amplia, consequentemente, as possibilidades de estratégias de cobrança e organizaçáo para a (re) construção das políticas públicas. 


\section{Curso de controle social e a relação com a rede}

Resgatando-se o caso exposto anteriormente sobre o contorno evasivo e sem o devido encaminhamento das denúncias apresentadas aos espaços de controle social, procedimento muitas vezes realizado por agentes ligados à gestão, apresenta-se um desafio considerável: como estruturar o curso para que os participantes possam possuir subsídios instrumentais para dar o devido encaminhamento às suas denúncias, mesmo à revelia de opiniốes, muitas vezes contaminadas por interesses políticos de determinados segmentos, presentes nos espaços de controle social? Como instrumentalizar os participantes para ampliar a potência de sua participação nos espaços de controle social e, com isso, proporcionar guias para as políticas públicas?

Esta pergunta acompanhou nosso processo de amadurecimento ${ }^{2}$ e reposicionou açôes e a formatação do curso. Algumas referências podem proporcionar subsídio ao leitor quanto à elaboração destas respostas (INSTITUTO..., 2003). O site da AADOM (ASSOCIAÇÃO..., 2015) apresenta, em detalhes, formas de acionamento de outras instâncias de apoio ao controle das açóes públicas em sua área de ação.

No tocante ao curso, foram direcionadas, como um de seus eixos formativos, açôes para fortalecer o vínculo dos participantes com outras instituições, objetivando proporcionar subsídios para a especialização do exercício do controle social. Nas primeiras turmas do curso, foram realizadas explanaçóes sobre as funçôes e formas de encaminhamento de denúncias para equipamentos, como o Ministério Público, o Tribunal de Contas, a Ouvidoria, os Conselhos de Fiscalização Profissional, o Conselho Municipal de Saúde, a Vigilância Sanitária, a ANVISA, a Imprensa, as Associaçôes de defesa dos direitos humanos, entre outros.

Atualmente com maior contato com a rede, são convidadas pessoas parceiras para procurar ampliar a relação dos participantes com estes espaços. Os convidados realizam falas sobre as premissas e o funcionamento das instituiçôes as quais representam e as formas de acioná-las para proteção dos direitos humanos. A intençáo da apresentação pormenorizada e personalizada da rede é proporcionar, aos participantes, possibilidades mais efetivas de encaminhamento das denúncias levantadas a partir de sua vivência nos equipamentos de saúde e/ou nos espaços de controle social. Para além, tal organização proporciona estrategicamente ao terapeuta ocupacional, assim como aos participantes, maior conhecimento e organicidade junto à rede de proteçâo dos direitos humanos. Esta é uma das conquistas mais maduras do trabalho tecido em espaço de tempo mais amplo.

Para além do convite aos representantes, uma sugestáo considerada profícua seria a possibilidade - a qual não realizamos até o momento no curso - de organizar saídas junto com os participantes do grupo/curso para as citadas instituiçóes. Com isso, a práxis do encaminhamento de denúncias, tão distante de nossa formação social usual, pode ser fortalecida. Para além, tais instituiçóes, mesmo que diferentes das intrinsecamente relacionadas às do Controle Social, podem dar suporte ao exercício da conduçáo das políticas públicas, afirmando-se como estruturas de apoio para a cobrança e a construção das políticas públicas.

Pode ser trabalhada, ainda, a formatação das denúncias, dos dossiês e de outros documentos, necessária ao seu encaminhamento a esses diferentes espaços, enquanto conteúdo dos encontros/curso, proporcionando suporte estrutural aos participantes para realizar, de maneira mais concisa, a defesa dos direitos humanos. Em nossa experiência, o curso foi espaço ímpar para a apreensão de diversas dificuldades da rede, apresentadas pelos participantes, as quais puderam ser encaminhadas para os equipamentos responsáveis.

\section{Desfechos possíveis}

O curso/grupo realizado nos CAPS/UBS/ CRAS/Associações ou outra instituição, uma vez que possibilite o fortalecimento dos indivíduos e do grupo na defesa dos direitos humanos, pode tornar-se embrião da formação de associaçóes e/ou conselhos locais. E aqui se preveem outros desafios.

Em nossa experiência, vimos trabalhando a importância da constituição e/ou fortalecimento de Associaçóes para defesa dos direitos humanos junto aos participantes do curso. $\mathrm{Na}$ experiência que o leitor possa assumir, caso haja interesse na formação de associaçóes pelos participantes, o rumo das ações pode inclinar-se para garantir apoio, pelo menos em primeiro momento, junto aos caminhos legais para a realização desta empreitada. Desta maneira, o movimento dos usuários se fortalece e as cobranças de açóes públicas podem passar a se dar com maior ênfase. Acreditamos ser possível, como engate deste trabalho, até mesmo auxiliar a associação em seus primeiros passos para a captação de recursos e configurar um site, por exemplo, com espaços de denúncia, o que aproximaria estes representantes do restante dos usuários, potencializando a cobrança de ações públicas para a resolução dos casos que chegariam até a associação. 


\section{Conclusão}

O desenho metodológico que aqui foi desenhado não pretende sobremaneira prescrever fórmulas que contenham ou limitem o potencial criativo da realizaçáo de açóes voltadas ao fortalecimento do controle social das açôes públicas. O percurso de cada profissional junto ao controle social e os desafios próprios a cada uma das regióes exigirão, sem dúvidas, ações específicas e inovadoras.

No limite da exposição desta experiência de trabalho, de alguns anos voltados ao tema do controle social, com ênfase dada à saúde mental, procurou-se, neste momento, apresentar algumas diretrizes que possam contribuir para o exercício de práticas em saúde voltadas a fortalecer populaçóes em vulnerabilidade social, no sentido de ampliar seu empoderamento comunitário.

Embora não trabalhado neste manuscrito em densidade, o que será reservado a outro momento, ressalta-se a proficuidade do envolvimento da Universidade junto ao enfrentamento conjunto das problemáticas próprias ao controle social. Tal registro afirmou a potência da formação conjunta dos participantes e ministrantes, da aproximação das diferentes instituições, das lideranças e problemáticas territoriais, as quais puderam subsidiar açóes diversas e criar paulatinamente uma rede de proteção aos direitos da pessoa com transtorno mental.

Ao leitor que se afeiçoar ao tema, fica o alerta: diversos desafios serão enfrentados. A previsão legal do controle social não garante sua aplicaçáo pragmática, pois relações de poder diversas não são diluídas com a aprovação nacional de uma lei. A verticalizaçáo do poder nas açôes públicas, muitas vezes conjugada intrínseca e exclusivamente ao momento histórico-social brasileiro da ditadura, para longe da extinção, se pulveriza cotidianamente na prática do controle social, assim como nos estabelecimentos de saúde diversos.

As relaçóes de poder poderão ser vivenciadas pelo leitor quando, em seu próprio exercício funcional, usuários iniciarem, embora de maneira frutífera, movimentos reivindicatórios para adequar determinados funcionamentos previstos legislativamente e inoperantes nos serviços que utilizam. O profissional, com isso, terá seu trabalho, embora em êxtase, exposto e poderá enfrentar algumas repercussōes/represálias.

Como munir usuários a conhecer, por exemplo, seu direito ao funcionamento do CAPS das $8 \mathrm{~h}$ às $18 \mathrm{~h}$, quando o serviço que você trabalha funciona das $8 \mathrm{~h}$ às $16 \mathrm{~h}$ ? Como apresentar a equipe mínima legal ao usuário, quando seu CAPS trabalha com equipe que não chega à sua numeração? Se o trabalho for conciso, a reivindicação será certa. Contudo, tanto o gestor como os demais profissionais, caso não estejam preparados para compreender a importância de tal mobilização para a composição parceira da gestão em rede, poderão visualizar o trabalho do profissional, agora efetivo, com olhos náo agradáveis - e a relação de poder pode apresentar-se incisiva e as represálias, diversas. Embora o trabalho apresentado neste material tenha sido direcionado a compor ações junto aos usuários/familiares dos serviços, é importante o alerta: é interessante trabalhar, anteriormente ou, no mínimo, concomitantemente, sua equipe quanto ao tema. Sem as devidas atenção e elaboração estratégica, tal trabalho e processo, por mais edificantes de parcerias para a construção coletiva do SUS, poderáo deparar-se com forças imobilizantes, as quais afirmarão, sobremaneira, a situação dos profissionais como representantes do Estado e sua pertença à manutençáo das normas institucionais, desafiando, no fio da navalha, o fortalecimento da população e, acima de tudo, da diretriz do Controle Social.

Outra sugestão que pode ser interessante, ao agora receoso leitor, é realizar prévio levantamento das lideranças comunitárias e associaçôes representativas da comunidade, e propor parceria para a realização deste trabalho - com isto, por um lado, se a proteção espacial na realização do grupo/encontro/curso nestas associaçóes pode proporcionar certo escudo ao profissional, por outro, as próprias lideranças podem adensar o escudo através da exigência do trabalho, de sua continuidade e da presença do profissional neste processo -, ou seja, a rede de proteção dos direitos humanos deve ser fortalecida nas diversas nuances de seu espectro.

Para longe de inibir, restringir ou proporcionar, em seu desfecho, apreensões ao leitor para o exercício do trabalho que aqui se procurou delinear em uma de suas possíveis formas, intenção maior se dá na afirmação da necessidade de maturidade na área para evitar e/ou prever possíveis barreiras para que, com isso, o trabalho torne-se conciso e permanente. Pensar criativamente em possíveis contornos para evitar colisóes paralisantes deste profícuo processo torna-se mister para que o leitor, em sua competência potencializada, possa despender esforços emancipatórios e fortalecer a prevista "participação da população" no controle das açóes públicas para que, paulatinamente, possamos, em conjunto, construir um SUS de maior qualidade para todos nós. 


\section{Referências}

AMARANTE, P. A (clínica) e a reforma psiquiátrica. In: AMARANTE, P. (Org.). Archivos de saúde mental e atenção psicossocial. Rio de Janeiro: Nau Editora, 2003. p. 45-66.

ASSIS, M. M. A.; VILLA, T. C. S. O Controle Social e a demoratização da informação: um processo em construção. Revista Latino-americana de Enfermagem, Ribeirão Preto, v. 1, n. 3, p. 376-82, 2003.

ASSOCIAÇÃO DE APOIO AOS PORTADORES DE DISTÚRBIOS DE ORDEM MENTAL - AADOM. Disponível em: <www.aadom.org.br>. Acesso em: 17 maio 2015.

AVRITZER, L. Sociedade civil, instituições participativas e representação: da autorização à legitimidade da ação. Dados, Rio de Janeiro, v. 50, n. 3, p. 443-464, 2007.

BRASIL. Decreto-Lei ${ }^{\circ}$ 8.080, de 19 de setembro de 1990. Dispóe sobre as condiçóes para a promoção, proteção e recuperação da saúde, a organização e o funcionamento dos serviços correspondentes, e dá outras providências. Diário Oficial [da] República Federativa do Brasil, Brasília, DF, 20 set. 1990a. Disponível em: <http://www.planalto.gov.br/ccivil/LEIS/l8080.htm>. Acesso em: 5 mar. 2010.

BRASIL. Lei no 8.142, de 28 de dezembro de 1990. Dispóe sobre a participação da comunidade na gestão do Sistema Único de Saúde (SUS) e sobre as transferências intergovernamentais de recursos financeiros na área da saúde e dá outras providências. Diário Oficial [da] República Federativa do Brasil, Brasília, DF, 31 dez. 1990 b.

BRASIL. Ministério da Saúde. Guia do conselheiro: curso de capacitação de conselheiros estaduais e municipais de saúde. Brasília, 2002. Disponível em: <http://conselho. saude.gov.br/biblioteca/revistas/guia_conselheiro.pdf $>$. Acesso em: 8 fev. 2015.

BRASIL. Ministério da Saúde. A prática do controle social: Conselhos de Saúde e financiamento do SUS. Brasília, 2003a. Disponível em: <http://sna.saude.gov.br/ download/A_Pratica_Controle_Social.pdf $>$. Acesso em: 2 out. 2015.

BRASIL. Resolução n 333, de 04 de novembro de 2003. Aprova as diretrizes para criação, reformulação, estruturação e funcionamento dos Conselhos de Saúde. Diário Oficial [da] República Federativa do Brasil, Brasília, DF, 4 dez. 2003b. Disponível em: <http://conselho.saude. gov.br/biblioteca/livros/resolucao_333.pdf >. Acesso em: 1 dez. 2013.

BRASIL. Portaria n ${ }^{\circ} 3.088$, de 23 de dezembro de 2011. Institui a Rede de Atenção Psicossocial para pessoas com sofrimento ou transtorno mental e com necessidades decorrentes do uso de crack, álcool e outras drogas, no âmbito do Sistema Único de Saúde. Diário Oficial [da] República Federativa do Brasil, Brasília, DF, 30 dez. 2011.

BRASIL. Ministério da Saúde. Portaria n 130, de 26 de janeiro de 2012. Redefine o Centro de Atenção Psi- cossocial de Álcool e outras Drogas 24 h (CAPS AD III) e os respectivos incentivos financeiros. Diário Oficial [da] República Federativa do Brasil, Brasília, DF, 27 jan. 2012. Disponível em: <http://dtr2001.saude.gov.br/sas/ PORTARIAS/Port2005/PT-396.htm>. Acesso em: 1 dez. 2015.

BRAVO, M. I. S.; CORREIA, M. V. C. Desafios do controle social na atualidade. Serviço Social \& Sociedade, São Paulo, n. 109, p. 126-150, 2012.

CARVALHO, S. R. Os múltiplos sentidos da categoria "empowerment" no projeto de Promoção à Saúde. Cadernos de Saúde Pública, Rio de Janeiro, v. 20, n. 4, p. 1088-1095, 2004.

CORREIA, M. V. C. Controle Social na Saúde. In: MOTA, A. E. et al. (Org.). Serviço social e saúde: formação e trabalho profissional. São Paulo: Cortez: 2006. p. 111-138.

CORREIA, M. V. C. Que controle social? Os conselhos de saúde como instrumento. Rio de Janeiro: Fiocruz, 2000 .

CÔRTES, S. V. (Org.). Participação e Saúde no Brasil. Rio de Janeiro: Fiocruz, 2009.

FERRO, L. F. Trabalho territorial em hospitais psiquiátricos: construindo no presente um futuro sem manicômios. Psicologia: Ciência e Profissão, Brasília, v. 29, n. 4, p. 752-767, 2009.

INSTITUTO BRASILEIRO DE DEFESA DO CONSUMIDOR - IDEC. O SUS pode ser seu melhor plano de saúde. Brasília, 2003.

OLIVEIRA, G. N.O Projeto terapêutico como contribuição para a mudança das práticas de saúde. $2007.176 \mathrm{f}$. Dissertação (Mestrado em Saúde Coletiva) - Universidade Estadual de Campinas, Campinas, 2007.

OLIVEIRA, V. C. Comunicação, informação e participaçáo popular nos Conselhos de Saúde. Saúde e Sociedade, São Paulo, v. 13, n. 2, p. 56-69, 2004.

PEDRINI, D. M.; ADAMS, T.; SILVA, V. R. (Org.). Controle Social de politicas públicas: caminhos, descobertas e desafios. São Paulo: Paulus, 2007.

SANTOS, C. C. S.; BASTOS, R. L. Participação social: a construção da democracia na saúde brasileira. Revista Brasileira em Promoção da Saúde, Fortaleza, v. 24, n. 3, p. 266-273, 2011.

SILVA, A. X.; CRUZ, E. A.; MELO, V. A importância da informação em saúde para o exercício do controle social. Ciência \& Saúde Coletiva, Rio de Janeiro, v. 12, n. 3, p. 683-688, 2007.

VALLA, V. V. Controle social ou controle público? In: DE SETA, M. H.; PEPE, V. L. E.; OLIVEIRA, G. O. D. Gestão e vigilância sanitária: modos atuais do pensar e fazer. Rio de Janeiro: Fiocruz, 2006. p. 49-59.

VIDAL, C. E. L.; BANDEIRA, M.; GONTIJO, E. D. Reforma psiquiátrica e serviços residenciais terapêuticos. Jornal Brasileiro de Psiquiatria, Rio de Janeiro, v. 57, n. 1, p. 70-79, 2008. 


\section{Fonte de financiamento}

Pró-Reitoria de Extensão e Cultura da Universidade Federal do Paraná (PROEC-UFPR).

\section{Notas}

${ }^{1}$ Ao exemplo da Conferência Municipal de Saúde de Curitiba, realizada em 2011, com o tema: SUS - Patrimônio do povo brasileiro/Controle Social em Curitiba - 20 anos de construção. A Conferência Municipal de Curitiba, no ano de 2013, previu, também, como um dos eixos de trabalho, a Gestão participativa, controle social e descentralização da gestão.

${ }^{2}$ Cabe explicitar que tal processo foi estabelecido em bases dialógicas com os integrantes do curso de maneira frequente, durante sua realizaçáo, e, em seu desfecho, por meio de pesquisa realizada com os participantes. 